\title{
Translation and validation of the Arabic version of the 5-item Oral Health Impact Profile: OHIP5-Ar
}

\author{
Mohammed Nasser Alhajj ${ }^{\text {* }}$ (D, Esam Halboub ${ }^{2}$, Nadia Khalifa ${ }^{3}$, Abdullah G. Amran ${ }^{4}$, Daniel R. Reissmann ${ }^{5}$, \\ Abbas G. Abdullah ${ }^{6}$, Mounzer Assad ${ }^{7}$, Abdulghani A. Al-Basmi ${ }^{8}$ and Fawaz A. Al-Ghabri ${ }^{4}$
}

\begin{abstract}
Purpose: The aim of this study was to translate and validate an Arabic version of the 5-item Oral Health Impact Profile (OHIP).

Methods: A total of 320 subjects (aged 18 years and above) were consecutively recruited from dental clinics. The self-administered OHIP5-Ar was distributed and the data were collected and analyzed. The dimensionality of the instrument was investigated using confirmatory factor analyses (CFA). Reliability was assessed as the instruments internal consistency using Cronbach's alpha and test-retest-reliability using intraclass correlation coefficient (ICC). Convergent validity was tested by correlation between perceived global oral and general health questions with the latent factor (OHRQoL) using structural equation modelling analysis and with OHIP5-Ar total score using spearman's correlation coefficient. Known-groups validity was tested among groups with known differences and sensitivity to change was also investigated after dental treatments.
\end{abstract}

Results: The OHIP5-Ar was fitted well in the unidimensional model as indicated by the CFA with fit indices (RMSEA: 0.00, SRMR: 0.010, GFI: 0.998, TLI: 1). Cronbach's alpha was 0.78 and the ICC agreement was 0.88 . The validity tests indicated satisfactory validity of the instrument and the sensitivity to change of the instrument revealed significant change in the OHIP5-Ar total score after the provision of dental treatments (effect sizes: 0.55-1.49).

Conclusion: The OHIP5-Ar showed satisfactory psychometric properties among Arabic-speaking population. This instrument is sensitive to the changes of oral health and can be used to measure the OHRQoL with one total score.

Keywords: OHRQoL, OHIP5, Translation, Arabic version, Questionnaire

\section{Background}

Quality of Life (QoL) is defined as individuals' perception of their position in life with regard to the culture and value systems where they live, and in relation to their goals, expectations, standards and concerns [1]. It is not a simple concept; instead, it is a broad-ranging concept influenced in a complex way by the individuals' physical health, psychological state, level of dependence, social relationships, and their relationships to salient features of the surrounding environment [1-3]. Primarily and directly oral health can affect the general health

\footnotetext{
* Correspondence: m.n.alhajj@hotmail.com

${ }^{1}$ Department of Prosthodontics, Faculty of Dentistry, Thamar University,

Dhamar, Yemen

Full list of author information is available at the end of the article
}

resulting in positive or negative impact on the individuals' QoL, that is, they can eat, talk and conduct daily social activities without discomfort or embarrassment $[1,4]$. When QoL is linked to health and disease, it is referred to as Health-Related Quality of Life (HRQoL). This term is useful to differentiate it from other QoL aspects. HRQoL is a multidimensional concept including physical, mental/ emotional, and social functioning domains. It refers to the impact of health status on the individual's quality of life [5-7].

A part of HRQoL is Oral Health-Related Quality of Life (OHRQoL), which is a multidimensional concept referring to patient's perceptions when eating, sleeping, or engaging in social activities with respect to oral health [8-10]. The Oral Health Impact Profile

(c) The Author(s). 2019 Open Access This article is distributed under the terms of the Creative Commons Attribution 4.0 International License (http://creativecommons.org/licenses/by/4.0/), which permits unrestricted use, distribution, and reproduction in any medium, provided you give appropriate credit to the original author(s) and the source, provide a link to the Creative Commons license, and indicate if changes were made. The Creative Commons Public Domain Dedication waiver (http://creativecommons.org/publicdomain/zero/1.0/) applies to the data made available in this article, unless otherwise stated. 
(OHIP) is the most widely used instrument to measure OHRQoL [8]. Based on Locker's conceptual model of oral health [11], Slade and Spencer developed and validated the original 49-item OHIP (OHIP49) [12]. It has been validated culturally and linguistically; its psychometric properties have been tested and it has been used in both cross-sectional and longitudinal studies [13-16]. The OHIP is usually used to evaluate the impact of oral disease on quality of life and to measure the outcomes of clinical interventions [17-19]. Despite the fact that it has been widely used and accepted, in addition to being comprehensive and precise when measuring OHRQoL, it is long and hence it is time-consuming, more prone to missing data, inconvenient, it costs more, and may causes problems especially to elderly respondents [20]. For the afore-mentioned reasons, several short forms of OHIP were created [20-23].

The shortest version of this instrument is the 5-item OHIP which, as its name implies, consists of 5 questions representing the four suggested dimensions: Oral Function, Orofacial Pain, Orofacial Appearance and Psychosocial Impact [24, 25]. It has only $10 \%$ of the original instrument items but can capture almost $90 \%$ of the information. This makes it a more accepted and attractive instrument for efficient OHRQoL assessment. It has been tested and validated in a Swedish general population [14], Japanese prosthodontic patients [26], Dutch temporomandibular dysfunction (TMD) patients [27], German general population and TMD patient [23], and a US adult general population [28]. So far, there has not been any information about the Arabic version of this ultra-short instrument.

The aim of this study, therefore, was to translate an Arabic version of the 5-item OHIP and to test its psychometric properties among an Arabic-speaking population.

\section{Materials and methods}

\section{Translation of the OHIP5 into Arabic}

Our version was translated from the English version published by Naik et al. [28] using a forward-backward approach [29]. A team of four fluent bilingual dentists were independently involved in this part of the study. The English version was translated to Arabic by two translators. The resulting versions were reviewed and integrated into one version. This version was backward translated to English by the other two translators who had no access to the English version. Similar to the forward translation, the resulting versions were reviewed and integrated into one version. Both forward and backward versions were revised and a consensus was achieved about discrepancies. Similar to the English version, responses to the OHIP5-Ar questions were made on a 5 -point Likert scale $(0=$ never; $1=$ hardly ever; $2=$ occasionally; 3 = fairly often; and $4=$ very often).

A comparison regarding content and wording between the translated OHIP5 items and the corresponding items in the longer forms of the Arabic versions $[30,31]$ was performed to make sure that they are equivalent. The initially developed Arabic-language version was piloted on a convenience sample. Thirty subjects were involved and their comments were received and addressed. The final Arabic-language version of the instrument (OHIP5-Ar) was then finalized and prepared for the main study (Appendix). The piloted subjects were not involved in the main study.

\section{Patient involvement and data collection}

The study comprised 320 subjects aged 18 years and older. This number of participants exceeded the recommended subject to item ratio (2-20 subjects per item) which is needed to perform factor analyses [32-34]. They were recruited consecutively from patients and their accompanying persons who attended one specialist and two general dental clinics in Dhamar city, Yemen. The protocol of this study was approved by Ethics Committee of the Faculty of Dentistry, Thamar University (Ref: 2016009). Before commencing the study, its aims were explained to the participants and they were asked to give their informed consent. In addition to the OHIP5-Ar questions, the questionnaire included sociodemographic questions and two global questions related to perceived oral and general health status reported on an ordinal 5-point scale ('poor', 'fair', 'good', 'very good', and 'excellent') [31, 35, 36]. All participants were subjected to clinical assessment which included the periodontal status and number and location of missing teeth (anterior or posterior). For evaluation of gingival inflammation and periodontal attachment loss, the diagnostic criteria of the periodontal index were applied [37]. Number of present teeth were classified as $<20$ teeth or $\geq 20$ teeth $[38,39]$. One specialist in periodontics and two other well-trained authors performed the examination.

\section{Statistical analysis \\ Reliability}

The reliability of the OHIP5-Ar was assessed using internal consistency and test-retest reliability. Cronbach's alpha and inter-item correlation were used for internal consistency. Values of Cronbach's alpha $\geq 0.70$ were considered satisfactory [40], and for inter-item correlation, values $>0.20$ were considered acceptable [41]. Based in a one-way random-effects ANOVA, the intraclass 
correlation coefficient (ICC) were calculated to determine test-retest reliability. A convenience sample of thirty subjects were selected for this test with a 2 weeks interval between the two assessments and no treatment performed in between. To ensure that, this group was selected from co-patients. However, only 26 subjects were available for second assessment. Values of ICC of $>0.80$ indicate excellent agreement, good agreement with values from 0.61 to 0.80 , moderate agreement with values from 0.41 to 0.60 , and poor agreement with values $<0.40$ [42]. Subjects recruited for the reliability test were not included in the main study.

\section{Validity}

Since OHIP5 has one dimension, one OHIP summary score is sufficient to express the individual's OHRQoL [23]. With this regard, construct validity and dimensionality of the OHIP5-Ar were assessed by confirmatory factor analysis (CFA). All items of the OHIP5-Ar were loaded to one latent factor representing OHRQoL. The model fit was evaluated using a set of indices including: good of fitness index (GFI), standardized root mean square residual (SRMR), root mean square error of approximation (RMSEA), incremental fit index (IFI) which is considered analogous to $\mathrm{R}^{2}$, and Tucker-Lewis index (TLI). The following values were suggested as guidelines for model fit: GFI $\geq 0.95$, SRMR $\leq 0.08$, RMSEA $\leq 0.06$, IFI $\geq 0.95$ and TLI $\geq 0.95$ [43-46]. The latent factor was considered to have a mean of 0 and a variance of 1 for identification purpose. To improve the model fit and to avoid overestimation or underestimation of the model [4751], correlation between measurements errors (e1 and e2, e1 and e5, e2 and e5) were allowed.

Convergent validity was assessed by Spearmen's rank correlation between summary score of the OHIP5-Ar and both global questions of perceived oral and general health status. The global general health question was included considering that this question implicitly includes the oral health status as a part of the general health. Moreover, it is well known that there is a considerable correlation between perceived oral health and general health [52-54]. The structural equation modelling analysis (SEM) was also performed using one latent factor representing OHRQoL and was correlated with global oral and general health questions. The above mentioned indices and guidelines were followed for model fit.

For known-groups validity, the differences between OHIP5-Ar summary scores of different groups expected to have different OHRQoL impairment were assessed. We compared OHIP5-Ar summary scores between subjects who had $\geq 20$ teeth and those who had $<20$ teeth $[55,56]$, subjects with periodontal problems and those with healthy periodontium $[57,58]$, subjects with age $\leq$
40 years and those with age $>40$ years $[55,59]$, subjects with anterior missing teeth (affecting esthetic appearance) and those with posterior missing teeth [56, 6063], and subjects with different educational status would have different values of OHRQoL [64, 65].

\section{Sensitivity to change}

It was hypothesized that responses of patients to OHIP5-Ar and thus OHRQoL will change after the provision of dental treatments. Thirty patients with different treatment needs were selected to assess sensitivity to change of the OHIP5-Ar. They were asked to fill the questionnaire at the first visit before starting any dental treatment and to refill it again after a recall period of 10 days to 1 month. The dental treatments included: gingivectomy $(n=5)$, anterior fixed partial denture $(n=10)$, posterior fixed partial denture $(n=10)$, and complete denture prosthesis $(n=5)$. The effect size (Cohen's d) was calculated using the following equation: (mean of baseline OHIP score - mean of follow-up OHIP score) / standard deviation of the baseline OHIP score [66]. According to Cohen, an effect size of $d=0.2$ is considered to be small, 0.5 is medium, and 0.8 is large.

Test of normality revealed non-normal distribution of the data so that non-parametric tests were used as appropriate. Statistical tests and path analysis were performed using statistical software (IBM SPSS Statistics v22 and AMOS v23; IBM Corp) ( $\alpha=0.05$ for all tests).

\section{Results}

\section{Subjects characteristics}

The majority of participants were female $(73.1 \%)$ and married (73.4\%) (Table 1). Mean age was $32.0 \pm 13.2$ years. Educational status varied among the participants (more proportions were in secondary and university levels). Most participants had $\geq 20$ teeth (83.1\%), missing posterior missing teeth $(74.4 \%)$, and periodontal problems (73.1\%). Regarding the global questions of oral and general health, most participants reported them as good.

\section{Reliability}

Cronbach's alpha of the OHIP5-Ar was 0.78 ranging from 0.71 to 0.78 when single items were deleted (Table 2), indicating satisfactory internal consistency for the entire instrument. Inter-item correlation between each pair of two items ranged from 0.33 to 0.65 . All inter-item correlations were found to be above the recommended value of 0.20 (Table 3).

With respect to test-retest-reliability, the ICC of 0.88 for the OHIP5-Ar summary score and 0.74 to 0.97 for the single items indicated excellent agreement between the two assessments. Using Paired $t$ test, all differences between both readings were minimum and insignificant $(\mathrm{P}>0.05)$ (Table 4). 
Table 1 Characteristics of the study sample

\begin{tabular}{|c|c|c|}
\hline & $\mathrm{N}$ & $\%$ \\
\hline \multicolumn{3}{|l|}{ Gender } \\
\hline Male & 86 & 26.9 \\
\hline Female & 234 & 73.1 \\
\hline \multicolumn{3}{|l|}{ Marital status } \\
\hline Single & 85 & 26.6 \\
\hline Married & 235 & 73.4 \\
\hline \multicolumn{3}{|c|}{ Age group (years) } \\
\hline$<20$ & 41 & 12.8 \\
\hline $20-39$ & 128 & 40.0 \\
\hline $30-39$ & 70 & 21.9 \\
\hline $40-49$ & 32 & 10.0 \\
\hline $50-59$ & 31 & 9.7 \\
\hline$\geq 60$ & 18 & 5.6 \\
\hline \multicolumn{3}{|l|}{ Education } \\
\hline Illiterate & 49 & 15.3 \\
\hline Primary & 58 & 18.1 \\
\hline Preparatory & 60 & 18.8 \\
\hline Secondary & 75 & 23.4 \\
\hline University & 72 & 22.5 \\
\hline Above & 6 & 1.9 \\
\hline \multicolumn{3}{|c|}{ Number of remaining teeth } \\
\hline$\geq 20$ teeth & 266 & 83.1 \\
\hline$<20$ teeth & 54 & 16.9 \\
\hline \multicolumn{3}{|c|}{ Location of missing teeth } \\
\hline Anterior & 82 & 25.6 \\
\hline posterior & 238 & 74.4 \\
\hline \multicolumn{3}{|c|}{ Periodontal status } \\
\hline Healthy & 86 & 26.9 \\
\hline Unhealthy & 234 & 73.1 \\
\hline \multicolumn{3}{|c|}{ Perceived general health } \\
\hline Excellent & 55 & 17.2 \\
\hline Very good & 92 & 28.8 \\
\hline Good & 122 & 38.1 \\
\hline Fair & 42 & 13.1 \\
\hline Poor & 9 & 2.8 \\
\hline \multicolumn{3}{|c|}{ Perceived oral health } \\
\hline Excellent & 17 & 5.3 \\
\hline Very good & 43 & 13.4 \\
\hline Good & 111 & 34.7 \\
\hline Fair & 92 & 28.8 \\
\hline Poor & 57 & 17.8 \\
\hline
\end{tabular}

\section{Validity}

\section{Construct validity and dimensionality}

The data fit the unidimensional model well (GFI: 0.998, SRMR: 0.010, RMSEA: 0.00, IFI: 1, TLI: 1). All these indices indicate excellent fit of the model, unidimensionality, and that the OHIP5-Ar structure can be modeled well by one latent factor model. Standardized estimates ranged from 0.51 to 0.75 with small standard errors (0.05-0.10), indicating that all items were strong indicators of the latent OHRQoL factor (Fig. 1).

\section{Convergent validity}

The summary score of the OHIP5-Ar was highly and statistically significantly correlated to the single-item measure of perceived oral health $(r=0.44, P<0.001)$ (Table 5). Similarly, a statistically significant correlation was found between summary score of the OHIP5-Ar and perceived general health $(r=0.17, P<0.001)$. This correlation, however, was lower than that for perceived oral health, as expected. Moreover, age (as continuous variable) showed highly statistically correlation $(r=0.21$; $P<0.001)$ with the OHIP5-Ar indicating increase in the self-rating scores with age progress.

All items in the structural equation model were combined to one common (general) factor representing OHRQoL. Data fit the model quite well (GFI: 0.977, SRMR: 0.043, RMSEA: 0.075, IFI: 0.970, TLI: 0.937), even though the value for RMSEA was somewhat higher and the value for TLI somewhat lower than the threshold for excellent fit. The correlations between the latent factor (OHRQoL) and both perceived oral and general health items were substantial ( $r=0.49$ and $r=0.18$, respectively). These values were close to those resulting from Spearman's correlation test confirming that the OHIP5-Ar can be modeled by a latent factor (Fig. 2).

\section{Known-groups validity}

The analyses of the potentially different groups (missing teeth, location of the missing teeth, periodontal status, age, and educational status) revealed highly statistically significant differences indicating sufficient known-groups validity of the OHIP5-Ar (Table 6). As expected, patients with less teeth, missing anterior teeth or periodontal problems had more problems and thus lower OHRQoL than the corresponding patient groups.

\section{Sensitivity to change}

Pre-treatment summary scores of the OHIP5-Ar increased significantly after the provision of different dental treatments. The mean difference of the OHIP5-Ar summary scores between pre- and post-treatment was $6.2 \pm 4.9$ (effect size: $1.31, P<0.001$. Effect sizes of the individual items ranged from 0.55 to 1.49 indicating 
Table 2 Means, SD, floor and ceiling effect, and Cronbach's alpha of OHIP5-Ar items

\begin{tabular}{llllll}
\hline & Mean \pm SD & Range & \multicolumn{2}{l}{ Floor and ceiling effect } & \multirow{2}{*}{ Cronbach's Alpha if Item Deleted } \\
\cline { 5 - 6 } & & & \% of value 0 & \% of value 4 & \\
\hline Difficulty chewing & $1.67 \pm 1.43$ & $0-4$ & 33.4 & 12.2 & 0.72 \\
Painful aching & $1.54 \pm 1.29$ & $0-4$ & 30.6 & 7.5 & 0.71 \\
Uncomfortable about appearance & $1.56 \pm 1.43$ & $0-4$ & 35.6 & 12.2 & 0.78 \\
Less flavor in food & $1.05 \pm 1.23$ & $0-4$ & 50.0 & 5.3 & 0.73 \\
Difficulty doing usual jobs & $0.90 \pm 1.16$ & $0-4$ & 53.4 & 3.8 & 0.76 \\
\hline
\end{tabular}

$S D$ standard deviation; Total Cronbach's alpha $=0.78$

moderate to large effects of the intra-individual differences between the two assessments (Table 7). Moreover, all effect sizes exceeded the threshold of 0.5 for a clinically relevant change [67].

\section{Discussion}

This is the first study assessing the psychometric properties of the OHIP5 in its Arabic version. Findings indicate satisfactory validity of the instrument suggesting its use as one total score to assess the OHRQoL in Arabic-speaking population. Our findings are well comparable to those from other studies on the 5-item OHIP. The dimensionality test of OHIP5-Ar revealed a one-dimensional instrument containing five items, each referring to at least one of the four suggested dimensions of the longer versions. Similar results were found in the English [28] and German [23] versions of the OHIP5. The internal consistency of the OHIP5-Ar was 0.78 indicating satisfactory construct validity of the instrument. This value is higher than that of the Dutch version [27] which was 0.67 , lower than that of the Japanese version [26] which was 0.81 , but it is close to the German [23], Swedish [14], and English [28] versions $(0.76,0.77$, and 0.75 , respectively). The average inter-item correlation was 0.42 which is similar to the Swedish version (0.41) [14]. The ICC of 0.88 was somewhat higher than that of the Dutch [27], German [23], and Japanese [26] versions. But differences were not considered relevant.
Correlation between summary score of the OHIP5-Ar and global perceived oral health question was close to that resulted from the latent variable analysis, indicating fit of the model for the target population. Similarly, the correlations between the summary score of the OHIP5-Ar and global general health question and that resulted from SEM analysis were close to each other. This confirms that the individual items of the OHIP5-Ar are able to measure the construct OHRQoL. The correlation between the OHIP5-Ar and global oral health is similar to those observed in the German $(r=0.50)$ [23] and Japanese $(r=0.48)$ [26] versions and higher than that found in the English version $(r=0.30)$ [28]. The SEM-based correlation, however, is close to that of the English version $(r=0.46)$ [28]. The OHIP5-Ar could clearly and significantly differentiate between different groups that have potential differences. It is well-known in the dental literature [56] that patients with more remaining teeth ( $\geq 20$ teeth) have better oral function than those with fewer remaining teeth $(<20$ teeth), and this will be primarily mirrored in their OHRQoL. In our study, patients with $\geq 20$ teeth had lower values of the OHIP5-Ar score (better oral health) than those who had $<20$ teeth. Esthetic appearance can also affect the individual's performance and thus the quality of life [61-63]. The OHIP5-Ar includes a question (Q3) related to esthetic which represents the orofacial appearance domain in the longer versions. Accordingly, patients who presented with missing posterior teeth reported better oral health than

Table 3 Inter-Item Correlation Matrix of OHIP5-Ar

\begin{tabular}{|c|c|c|c|c|c|}
\hline & $\begin{array}{l}\text { Difficulty } \\
\text { chewing }\end{array}$ & $\begin{array}{l}\text { Painful } \\
\text { aching }\end{array}$ & $\begin{array}{l}\text { Uncomfortable about } \\
\text { appearance }\end{array}$ & $\begin{array}{l}\text { Less flavor } \\
\text { in food }\end{array}$ & $\begin{array}{l}\text { Difficulty doing } \\
\text { usual jobs }\end{array}$ \\
\hline Difficulty chewing & 1.00 & & & & \\
\hline Painful aching & 0.65 & 1.00 & & & \\
\hline Uncomfortable about appearance & 0.33 & 0.40 & 1.00 & & \\
\hline Less flavor in food & 0.47 & 0.48 & 0.34 & 1.00 & \\
\hline Difficulty doing usual jobs & 0.37 & 0.34 & 0.35 & 0.47 & 1.00 \\
\hline
\end{tabular}


Table 4 Test-retest of reliability and differences between OHIP5-Ar items readings

\begin{tabular}{|c|c|c|c|c|c|}
\hline OHIP5 & ICC & $95 \% \mathrm{Cl}$ & $P$ & Mean difference $\pm S D^{a}$ & $P$ \\
\hline$\overline{\mathrm{ALL}}$ & 0.88 & $0.80-0.94$ & $<0.001$ & & \\
\hline Difficulty chewing & 0.78 & $0.50-0.90$ & $<0.001$ & $0.31 \pm 0.97$ & 0.118 \\
\hline Painful aching & 0.79 & $0.54-0.91$ & $<0.001$ & $0.04 \pm 1.04$ & 0.852 \\
\hline Uncomfortable about appearance & 0.97 & $0.93-0.99$ & $<0.001$ & $0.00 \pm 0.49$ & 1.000 \\
\hline Less flavor in food & 0.74 & $0.42-0.88$ & 0.001 & $0.19 \pm 0.63$ & 0.134 \\
\hline Difficulty doing usual jobs & 0.84 & $0.65-0.93$ & $<0.001$ & $0.12 \pm 0.91$ & 0.523 \\
\hline Summary core & & & & $0.65 \pm 1.98$ & 0.104 \\
\hline
\end{tabular}

ICC Intraclass Correlation Coefficient, $S D$ standard deviation; $P$ value is significant at 0.05 level

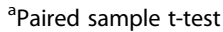

patients with missing anterior teeth. Similarly, patients with unhealthy periodontium reported worse OHRQoL than those did with healthy periodontium. Pain, bleeding, tooth mobility, calculus deposition, and gum recession were some of the clinical features of the diseased periodontium which reflected negatively on the patient's response. Increasing age is considered one of the contributing factors for poor oral health. This was obvious with our sample where patients $\leq 40$ years had lower values (positive response) of the OHIP5-Ar than those with age $>40$ years. Different values of oral health were observed among subjects with different educational levels. This was not surprising as an educated subject is likely to know more about oral health and care.

Sensitivity to change of the OHIP5-Ar was clearly confirmed in our sample. The effect of dental treatments on patients' response was moderate to large.

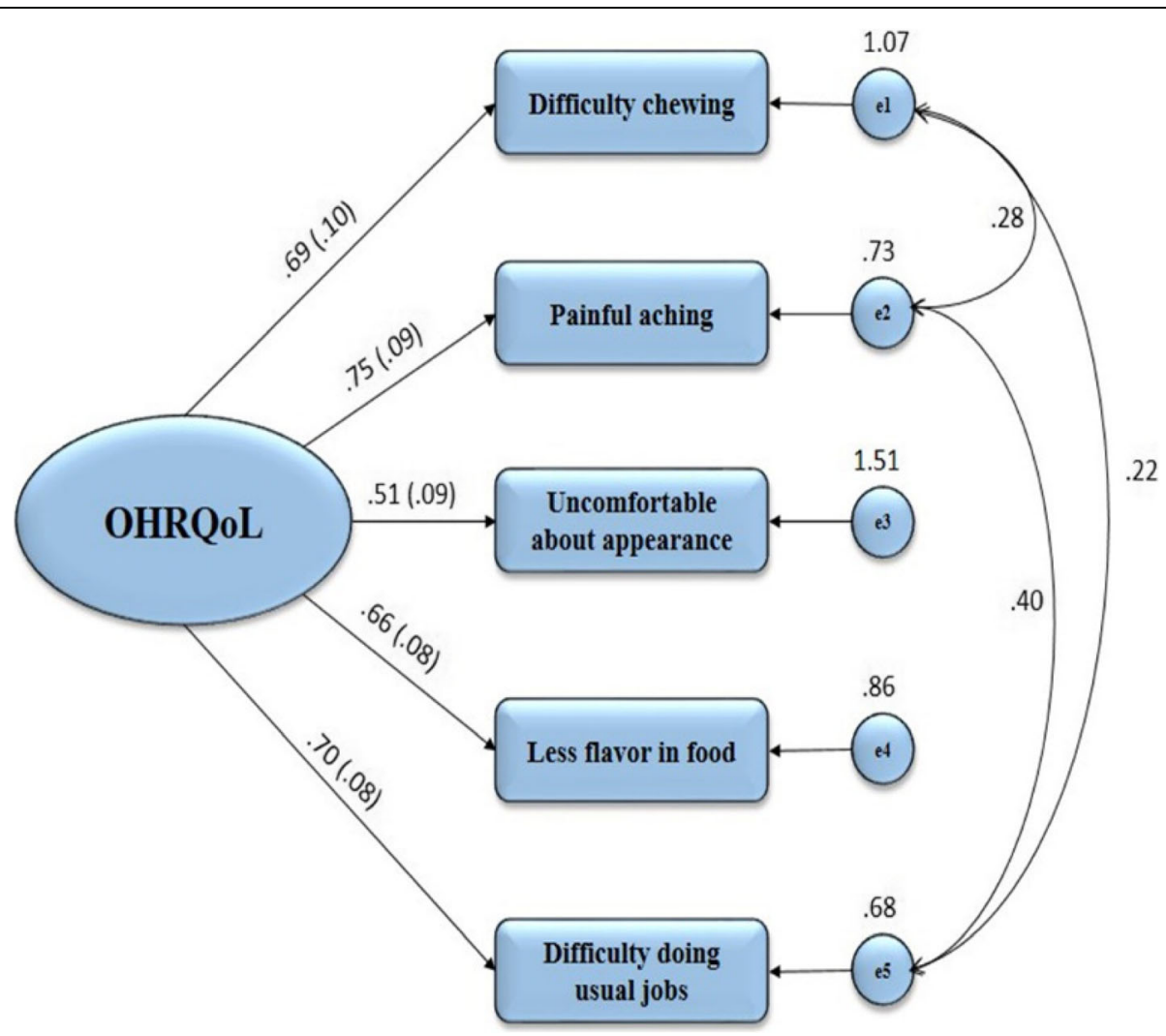

Fig. 1 Confirmatory factor analysis model of the oral health-related quality of life (OHRQoL) measured with the five-item OHIP. The latent factor $(\mathrm{OHRQOL})$ is presented in oval and the rectangles represents the measured indicators of the latent factor with their variance. The uni-directional lines arising from the latent factor refer to the factor loadings of the indicators (with their standard errors). Numbers on these lines refer to the standardized values 
Table 5 Convergent validity of OHIP5-Ar

\begin{tabular}{ccccc}
\hline & OHIP5 & \multicolumn{3}{l}{ Correlation Coefficient } \\
\cline { 3 - 5 } & Mean \pm SD & $r$ r $^{\text {a }}$ & $95 \% \mathrm{Cl}$ & $\mathrm{P}$ \\
\hline Perceived oral health $(n=320)$ & 0.44 & $(0.35-0.53)$ & $<0.001$ \\
Excellent $(n=17)$ & $0.65 \pm 0.60$ & & & \\
Very good $(n=43)$ & $0.83 \pm 0.68$ & & & \\
Good $(n=111)$ & $1.14 \pm 0.88$ & & \\
Fair $(n=92)$ & $1.41 \pm 0.81$ & & \\
Poor $(n=57)$ & $2.23 \pm 0.97$ & &
\end{tabular}

Perceived general health $(n=320) \quad 0.17 \quad(0.06-0.27) \quad<0.001$

$$
\begin{array}{ll}
\text { Excellent }(n=55) & 1.14 \pm 0.98 \\
\text { Very good }(n=92) & 1.15 \pm 0.86 \\
\text { Good }(n=122) & 1.51 \pm 0.94 \\
\text { Fair }(n=42) & 1.53 \pm 1.05 \\
\text { Poor }(n=9) & 1.44 \pm 1.05
\end{array}
$$

ICC Intraclass Correlation Coefficient, $S D$ standard deviation; $P$ value is significant at 0.05 level

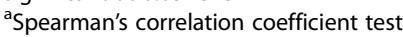

This effect is similar to that obtained in the German [23] and Japanese [26] versions. The relevant sample in our study received different types of dental treatments which is in contrast with the previous versions

\begin{tabular}{|c|c|c|c|}
\hline & $\mathrm{N}$ & Mean \pm SD & $P$ \\
\hline \multicolumn{4}{|l|}{ Missing teeth $^{a}$} \\
\hline$\geq 20$ teeth & 266 & $1.18 \pm 0.92$ & \multirow[t]{2}{*}{$<0.001$} \\
\hline$<20$ teeth & 54 & $2.15 \pm 0.70$ & \\
\hline \multicolumn{4}{|c|}{ Location of missing ${ }^{a}$} \\
\hline Anterior & 82 & $1.87 \pm 0.96$ & \multirow[t]{2}{*}{$<0.001$} \\
\hline Posterior & 238 & $1.16 \pm 0.89$ & \\
\hline \multicolumn{4}{|c|}{ Periodontal status ${ }^{\mathrm{a}}$} \\
\hline Unhealthy & 234 & $1.43 \pm 0.96$ & \multirow[t]{2}{*}{0.006} \\
\hline Healthy & 86 & $1.11 \pm 0.92$ & \\
\hline \multicolumn{4}{|l|}{$\mathrm{Age}^{\mathrm{a}}$} \\
\hline$\leq 40$ & 251 & $1.25 \pm 0.94$ & \multirow[t]{2}{*}{$<0.001$} \\
\hline$>40$ & 69 & $1.69 \pm 0.93$ & \\
\hline \multicolumn{4}{|l|}{ Education level $^{\mathrm{b}}$} \\
\hline Illiterate & 49 & $2.02 \pm 0.89$ & \multirow[t]{6}{*}{$<0.001$} \\
\hline Primary & 58 & $1.40 \pm 0.95$ & \\
\hline Preparatory & 60 & $1.24 \pm 0.98$ & \\
\hline Secondary & 75 & $1.18 \pm 0.98$ & \\
\hline University & 72 & $1.13 \pm 0.77$ & \\
\hline Postgraduate & 6 & $0.93 \pm 0.78$ & \\
\hline
\end{tabular}
of OHIP5 where patients received the same type of dental treatment (provision of new or remake a denture in the Japanese version and patient's with TMD
Table 6 Known-groups validity of OHIP5-Ar

$S D$ standard deviation, $P$ value is significant at 0.05 level

${ }^{\mathrm{a}}$ Mann-Whitney test; ${ }^{\mathrm{b}}$ Kruskal-Wallis test

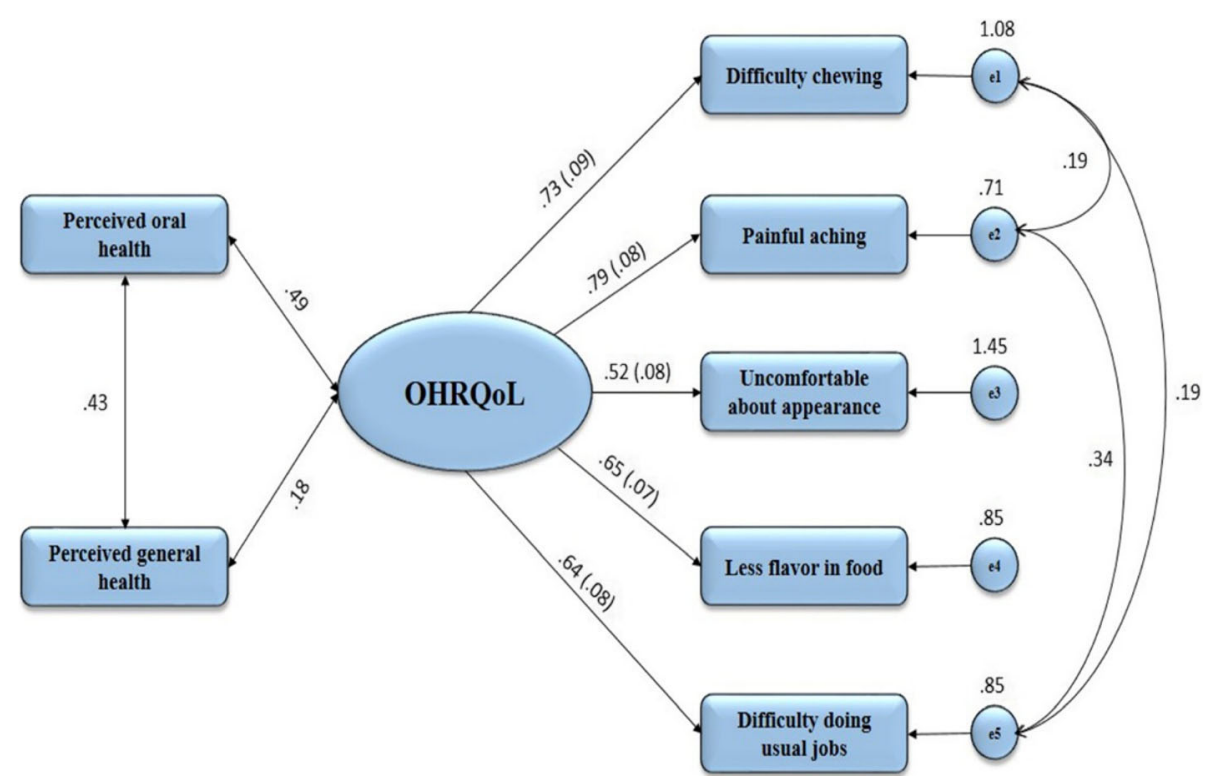

Fig. 2 Structural equation modelling (SEM) analysis for the correlation between perceived global oral and general health question and the latent factor (OHRQoL). The rectangles on the left represent perceived global oral and general health questions while the rectangles on the right represent the measured indicators of the latent factor with their variance. The uni-directional lines arising from the latent factor refer to the factor loadings of the indicators (with their standard errors). Number on these lines refer to the standardized values. The bidirectional lines refer to the correlation between perceived global oral and general health question and the latent factor (OHRQoL) 
Table 7 Sensitivity to changes of OHIP5-Ar (pre- and post-treatment)

\begin{tabular}{|c|c|c|c|c|c|}
\hline OHIP5 & Pre-treatment & Post-treatment & Mean difference & Effect size & $p^{a}$ \\
\hline Difficulty chewing & $2.07 \pm 1.46$ & $0.87 \pm 1.07$ & $1.20 \pm 1.45$ & 0.82 & 0.001 \\
\hline Painful aching & $1.80 \pm 1.16$ & $0.60 \pm 0.93$ & $1.20 \pm 1.30$ & 1.04 & $<0.001$ \\
\hline Uncomfortable about appearance & $2.50 \pm 1.46$ & $0.33 \pm 0.66$ & $2.17 \pm 1.66$ & 1.49 & $<0.001$ \\
\hline Less flavor in food & $1.33 \pm 1.30$ & $0.33 \pm 0.71$ & $1.00 \pm 1.08$ & 0.77 & $<0.001$ \\
\hline Difficulty doing usual jobs & $0.90 \pm 1.21$ & $0.23 \pm 0.63$ & $0.67 \pm 1.06$ & 0.55 & 0.002 \\
\hline Summary & $8.60 \pm 4.76$ & $2.37 \pm 3.19$ & $6.23 \pm 4.88$ & 1.31 & $<0.001$ \\
\hline
\end{tabular}

$P$ value is significant at 0.05 level; ${ }^{a}$ Wilcoxon Signed Ranks test

pain in the German version). The ability of OHIP5-Ar to predict the changes of different types of dental treatment has been proven in our study. It makes this instrument more suitable to be used in everyday dental practice. For assessing sensitivity to change, the time between intervention and recall assessment ranged from 10 days to 1 month. Even though the OHIP usually has a recall period of 1 month [23, 26], i.e., respondents are asked what they have experienced during the previous month and requiring at least 1 month between an intervention and the follow-up assessment to capture the entire treatment effect, changes in OHIP5-Ar summary scores were statistically significant and of moderate to large effect size. This also suggests that a shorter recall period (7 days) as suggested by Waller et al. [68], where patients are asked about their experiences during the previous week, could also be applied for the OHIP5-Ar. However, we believe that the ability of OHIP to detect the changes during this short period depends on the type of treatment itself. For example, adaptation to 3-unit fixed partial denture will take shorter time than adaptation to lower complete denture, and this will be definitely mirrored in the patient's response.

In comparison with the longer Arabic versions of this instrument which were validated by Al-Jundi et al. (OHIP49-Ar) [30] and Khalifa et al. (OHIP14-Ar), [31] the internal consistency of our version is higher than that of the OHIP49-Ar version (0.74), [30] and similar to that of the OHIP14-Ar (0.80). [31] The inter-item correlation and ICC agreement are also higher in our version. However, the correlation between OHIP5-Ar and both global oral and general health questions are lower than those found in the OHIP49-Ar version. [30] The OHIP14-Ar version [31] also reported highly significant correlations between these variables but no coefficients $(r)$ were mentioned. The higher correlation coefficients in the OHIP49-Ar version might be related to the number of questions (49 questions compared with 5 question) which can influence the relationships between these variables.
Dental status as well as dental treatment can greatly affect the individual's QoL. Dental caries [69], teeth missing [56], gum disease [70], aphthous ulcers [71], and temporomandibular disorders [72] are some examples of such pathologies that affect the QoL. Moreover, dental anxiety can also affect the individual perception of QoL [73]. On the other hand, many or almost all dental treatments can significantly improve the individual's QoL [74-77]. The current study has strengths and limitations. We used subjective measures of perceived oral and general health and objective measures of physical oral health status for validity assessments, what is considered a strength of the study. Furthermore, we applied sophisticated statistical analyses, i.e., SEM analysis and latent factor model. The sample size was sufficiently large to unambiguously prove reliability, validity, and sensitivity to change of the OHIP5-Ar. Our sample was recruited from specialist and general dental clinics attenders. A longer version of OHIP (OHIP14) was also validated among general dental clinics attenders in Scotland [78]. Although our study population could be considered a representative for dental patients, a community-based study with large sample size is recommended to validate the instrument among the general population. We didn't correlate the OHIP5-Ar to the long Arabic version (OHIP49-Ar). Since prior studies have reported a high correlation between short and long versions $[14,26$, 28], therefore this study did not focus on highlighting associations on this subject. Only one component (missing teeth) of the DMFT index was assessed, further studies could include this index to further validate the instrument.

\section{Conclusion}

The Arabic-language version of the OHIP5 is a valid and reliable instrument to assess OHRQoL in an Arabic-speaking population. Due to sufficient psychometric properties, low burdens, and easy applicability it can be recommended to be used in dental practice and for research purposes as well. 


\title{
Appendix
}

Table 8 Arabic Version of Oral Health Impact Profile 5 (OHIP5-Ar)

\section{Arabic Version of Oral Health Impact Profile 5 (OHIP5-Ar)}

\author{
الرجاء التكرم بوضع علامة (ل) على ما يتناسب مع رأيك حول النقاط التالية:
}

خلال الشهر الماضي، كم مرة عانيت من أي من المشاكل التالية:

How often have you had one or more of the following problem(s) during the last month?

\begin{tabular}{|c|c|c|c|c|c|}
\hline $\begin{array}{c}\text { دائماً } \\
\text { very often }\end{array}$ & $\begin{array}{l}\text { أغلب الأحيان } \\
\text { fairly often }\end{array}$ & $\begin{array}{l}\text { بعض الأحيان } \\
\text { occasionally }\end{array}$ & $\begin{array}{c}\text { hardly ever } \\
\text { hardl }\end{array}$ & $\begin{array}{l}\text { لا يوجد } \\
\text { never }\end{array}$ & 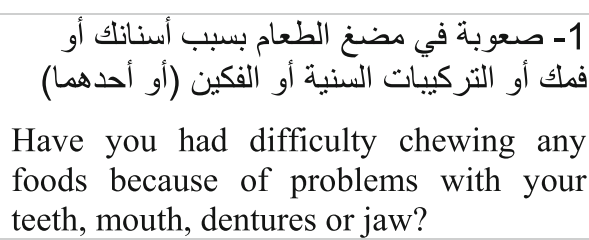 \\
\hline $\begin{array}{c}\text { دائماً } \\
\text { very often }\end{array}$ & $\begin{array}{l}\text { أغلب الأحيان } \\
\text { fairly often }\end{array}$ & $\begin{array}{c}\text { بعض الأحيان } \\
\text { occasionally }\end{array}$ & $\begin{array}{c}\text { hardly ever } \\
\text { hall }\end{array}$ & $\begin{array}{l}\text { لا يوجد } \\
\text { never }\end{array}$ & 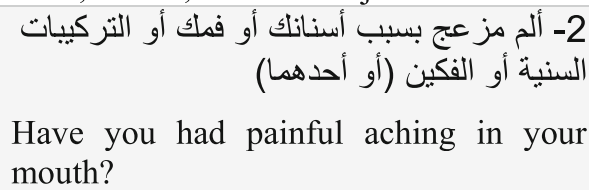 \\
\hline $\begin{array}{c}\text { دائماً } \\
\text { very often }\end{array}$ & $\begin{array}{l}\text { أغلب الأحيان } \\
\text { fairly often }\end{array}$ & $\begin{array}{c}\text { بعض الأحيان } \\
\text { occasionally }\end{array}$ & $\begin{array}{c}\text { نادراً } \\
\text { hardly ever }\end{array}$ & لا يوجد & 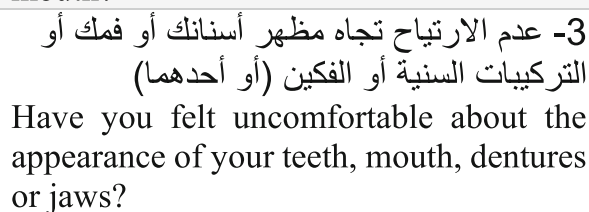 \\
\hline $\begin{array}{c}\text { دائماً } \\
\text { very often }\end{array}$ & $\begin{array}{l}\text { أغلب الأحيان } \\
\text { fairly often }\end{array}$ & $\begin{array}{c}\text { بعض الأحيان } \\
\text { occasionally }\end{array}$ & $\begin{array}{c}\text { hardly ever } \\
\text { halli }\end{array}$ & لا يوجد & 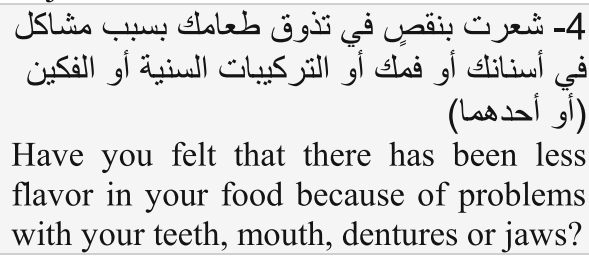 \\
\hline $\begin{array}{c}\text { دائماً } \\
\text { very often }\end{array}$ & $\begin{array}{l}\text { أغلب الأحيان } \\
\text { fairly often }\end{array}$ & $\begin{array}{c}\text { بعض الأحيان } \\
\text { occasionally }\end{array}$ & $\begin{array}{c}\text { hardly ever } \\
\text { hall }\end{array}$ & لا يوجد & 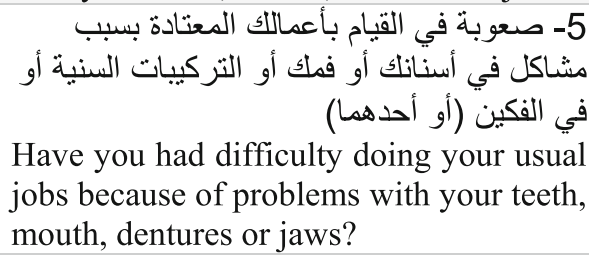 \\
\hline
\end{tabular}

\section{Abbreviations}

CFA: Confirmatory Factor Analysis; GFl: Goodness of Fit Index; ICC: Intraclass Correlation Coefficient; IFI: Incremental Fit Index; OHIP: Oral Health Impact Profile; OHRQoL: Oral Health-Related Quality of Life; QoL: Quality of Life; RMSEA: Root Mean Square Error of Approximation; SEM: Structural Equation Modelling; SRMR: Standardized Root Mean Square Residual; TLI: Tucker-Lewis Index; TMD: Temporomandibular Disorder

\section{Acknowledgments}

Not applicable.

\section{Funding}

Not applicable.

\section{Availability of data and materials}

The datasets supporting the findings of this article are available from the corresponding author.

\section{Authors' contribution}

MNA and EH participated in the design of the study, statistical analysis, interpretation of the data and drafted the manuscript. NK participated the interpretation of the data and drafted the manuscript. AGA participated in the design of the study, data collection, and drafted the manuscript. DRR participated in the development of the conceptual framework of the study, critically revised the manuscript and reviewed the final version of the manuscript. $A A A$, and FAA participated in the design of the study, data collection, and drafted the manuscript. AGA and MA participated the interpretation of the data and drafted the manuscript. All authors read and approved the final manuscript. 


\section{Ethics approval and consent to participate}

The study was approved by the Ethical Committee of Faculty of Dentistry, Thamar University (Ref: 2016009) and written consent forms were achieved from all participants.

\section{Consent for publication}

Not applicable.

\section{Competing interests}

The authors declare that they have no competing interests.

\section{Publisher's Note}

Springer Nature remains neutral with regard to jurisdictional claims in published maps and institutional affiliations.

\section{Author details}

'Department of Prosthodontics, Faculty of Dentistry, Thamar University, Dhamar, Yemen. ${ }^{2}$ Department of Maxillofacial Surgery and Diagnostic Sciences, College of Dentistry, Jazan University, Jazan, Saudi Arabia. ${ }^{3}$ Department of Preventive and Restorative Dentistry, Faculty of Dental Medicine, University of Sharjah, Sharjah, United Arab Emirates. ${ }^{4}$ Department of Periodontics, Faculty of Dentistry, Thamar University, Dhamar, Yemen. ${ }^{5}$ Department of Prosthetic Dentistry, University Medical Center Hamburg-Eppendorf, Hamburg, Germany. ${ }^{6}$ Department of Basic Sciences, Faculty of Dentistry, University of Khartoum, Khartoum, Sudan. ${ }^{7}$ Department of Oral Surgery, Faculty of Dentistry, Tishreen University, Lattakia, Syria.

${ }^{8}$ Private Dental Clinic, Dhamar, Yemen.

Received: 15 June 2018 Accepted: 8 November 2018

Published online: 20 November 2018

\section{References}

1. The World Health Organization Quality of Life assessment (WHOQOL). Position paper from the World Health Organization. Soc Sci Med. 1995; 41(10):1403-9.

2. Felce D, Perry J. Quality of life: its definition and measurement. Res Dev Disabil. 1995:16(1):51-74.

3. Felce D. Defining and applying the concept of quality of life. J Intellect Disabil Res. 1997:41(Pt 2):126-35.

4. Allen PF. Assessment of oral health related quality of life. Health Qual Life Outcomes. 2003;1:40.

5. Muragundi PM, Tumkur AM, Shetty RK, et al. Health-related quality of life measurement. J Young Pharm. 2012;4(1):54.

6. Taylor RM, Gibson F, Franck LS. A concept analysis of health-related quality of life in young people with chronic illness. J Clin Nurs. 2008;17(14):1823-33.

7. Andresen EM, Meyers AR. Health-related quality of life outcomes measures. Arch Phys Med Rehabil. 2000;81(12 Suppl 2):S30-45.

8. Al Shamrany M. Oral health-related quality of life: a broader perspective East Mediterr Health J. 2006;12(6):894-901.

9. Sischo L, Broder HL. Oral health-related quality of life: what, why, how, and future implications. J Dent Res. 2011;90(11):1264-70.

10. Rozier RG, Pahel BT. Patient- and population-reported outcomes in public health dentistry: oral health-related quality of life. Dent Clin N Am. 2008; 52(2):345-65 vi-vii.

11. Locker D. Measuring oral health: a conceptual framework. Community Dent Health. 1988;5(1):3-18.

12. Slade GD, Spencer AJ. Development and evaluation of the Oral health impact profile. Community Dent Health. 1994;11(1):3-11.

13. Allison $\mathrm{P}$, Locker $\mathrm{D}$, Jokovic $\mathrm{A}$, et al. A cross-cultural study of oral health values. J Dent Res. 1999;78(2):643-9.

14. Larsson P, John MT, Hakeberg M, et al. General population norms of the Swedish short forms of oral health impact profile. J Oral Rehabil. 2014;41(4): 275-81.

15. Slade GD, Spencer AJ, Locker D, et al. Variations in the social impact of oral conditions among older adults in South Australia, Ontario, and North Carolina. J Dent Res. 1996:75(7):1439-50.

16. MacEntee MI, Brondani M. Cross-cultural equivalence in translations of the oral health impact profile. Community Dent Oral Epidemiol. 2016; 44(2):109-18.

17. Tsakos G, Allen PF, Steele JG, et al. Interpreting oral health-related quality of life data. Community Dent Oral Epidemiol. 2012;40(3):193-200.
18. Tsakos G, Allen PF, Steele JG. What has oral health related quality of life ever done for us? Community Dent Health. 2013:30(2):66-7.

19. Vitti, RP., de Oliveira, ARB, Sinhoreti, MAC, et al. Oral health impact profile (OHIP-14) and its association with dental treatment needs of adolescents in a rural Nigerian community. 2017 2017;15(3):6\%J Braz J Oral Sci.

20. Locker D, Allen PF. Developing short-form measures of oral health-related quality of life. J Public Health Dent. 2002;62(1):13-20

21. Slade GD. Derivation and validation of a short-form oral health impact profile. Community Dent Oral Epidemiol. 1997;25(4):284-90.

22. Segu M, Collesano V, Lobbia S, et al. Cross-cultural validation of a short form of the Oral health impact profile for temporomandibular disorders. Community Dent Oral Epidemiol. 2005;33(2):125-30.

23. John MT, Miglioretti DL, LeResche L, et al. German short forms of the Oral health impact profile. Community Dent Oral Epidemiol. 2006;34(4):277-88.

24. John MT, Reissmann DR, Feuerstahler $L$, et al. Exploratory factor analysis of the Oral health impact profile. J Oral Rehabil. 2014;41(9):635-43.

25. John MT, Feuerstahler $\mathrm{L}$, Waller N, et al. Confirmatory factor analysis of the Oral health impact profile. J Oral Rehabil. 2014;41(9):644-52.

26. Baba K, Inukai M, John MT. Feasibility of Oral health-related quality of life assessment in prosthodontic patients using abbreviated Oral health impact profile questionnaires. J Oral Rehabil. 2008;35(3):224-8.

27. Van-Der-Meulen MJ, John MT, Naeije M, et al. Developing abbreviated OHIP versions for use with TMD patients. J Oral Rehabil. 2012;39(1):18-27.

28. Naik A, John MT, Kohli N, et al. Validation of the English-language version of 5-item Oral health impact profile. J Prosthodont Res. 2016; 60(2):85-91

29. Guillemin F, Bombardier C, Beaton D. Cross-cultural adaptation of healthrelated quality of life measures: literature review and proposed guidelines. J Clin Epidemiol. 1993;46(12):1417-32.

30. Al-Jundi MA, Szentpetery A, John MT. An Arabic version of the Oral health impact profile: translation and psychometric properties. Int Dent J. 2007 57(2):84-92

31. Khalifa N, Allen PF, Abu-bakr NH, et al. Psychometric properties and performance of the Oral health impact profile (OHIP-14s-ar) among Sudanese adults. J Oral Sci. 2013;55(2):123-32.

32. Kline P. Psychometrics and psychology. 7th ed. London: Academic Press; 1979.

33. Hair J, Anderson RE, TR L, et al. Multivariate Data Analysis. 7th ed. New York: Pearson; 1995

34. Anthoine $E$, Moret $L$, Regnault $A$, et al. Sample size used to validate a scale: a review of publications on newly-developed patient reported outcomes measures. Health Qual Life Outcomes. 2014;12:2.

35. Bowling A. Just one question: if one question works, why ask several? J Epidemiol Community Health. 2005:59(5):342-5.

36. Ahmad F, Jhaij AK, Stewart DE, et al. Single item measures of self-rated mental health: a scoping review. BMC Health Serv Res, 2014:14:398.

37. Russell AL. A system of classification and scoring for prevalence surveys of periodontal disease. J Dent Res. 1956:35(3):350-9.

38. World Health Organization. Recent advances in oral health. Report of a WHO expert committee. World Health Organ Tech Rep Ser 1992;826:1-37. https://www.ncbi.nlm.nih.gov/pubmed/1462607

39. Gotfredsen K, Walls AW. What dentition assures oral function? Clin Oral Implants Res. 2007;18(Suppl 3):34-45.

40. Bland JM, Altman DG. Cronbach's alpha. BMJ. 1997:314(7080):572.

41. Briggs SR, Cheek JM. The role of factor analysis in the development and evaluation of personality scales. J Pers. 1986;54(1):106-48.

42. Shrout PE, Fleiss JL. Intraclass correlations: uses in assessing rater reliability Psychol Bull. 1979:86(2):420-8.

43. $\mathrm{Hu}$ L, Bentler PM. Cutoff criteria for fit indexes in covariance structure analysis: conventional criteria versus new alternatives. Struct Equ Model Multidiscip J. 1999:6(1):1-55.

44. Hooper D, Coughlan J, Mullen M. Structural equation modelling: guidelines for determining model fit. EJBRM. 2008:6(1):53-60.

45. Barrett P. Structural equation modelling: adjudging model fit. Pers Individ Dif. 2007:42(5):815-24

46. Awang Z. Structural equation modeling using AMOS graphic. Malaysia: Penerbit Universiti Teknologi MARA; 2012. 230 p

47. Day NE, Wong MY, Bingham S, et al. Correlated measurement error-implications for nutritional epidemiology. Int J Epidemiol. 2004;33(6):1373-81.

48. Michels KB, Bingham SA, Luben R, et al. The effect of correlated measurement error in multivariate models of diet. Am J Epidemiol. 2004; 160(1):59-67. 
49. Rifkin RD. Effects of correlated and uncorrelated measurement error on linear regression and correlation in medical method comparison studies. Stat Med. 1995;14(8):789-98.

50. Gerbing DW, Anderson JC. On the meaning of within-factor correlated measurement errors. J Consum Res. 1984;11(1):572-80.

51. Reddy SK. Effects of ignoring correlated measurement error in structural equation models. Educ Psychol Meas. 1992;52(3):549-70.

52. Atchison KA, Gift HC. Perceived oral health in a diverse sample. Adv Dent Res. 1997;11(2):272-80.

53. De-Andrade FB, Lebrao ML, Santos $J$, et al. Relationship between oral health-related quality of life, oral health, socioeconomic, and general health factors in elderly Brazilians. J Am Geriatr Soc. 2012;60(9):1755-60.

54. Reissmann DR, John MT, Schierz O, et al. Association between perceived oral and general health. J Dent. 2013;41(7):581-9.

55. Steele JG, Sanders AE, Slade GD, et al. How do age and tooth loss affect oral health impacts and quality of life? A study comparing two national samples. Community Dent Oral Epidemiol. 2004;32(2):107-14.

56. Batista MJ, Lawrence HP, de Sousa Mda L. Impact of tooth loss related to number and position on oral health quality of life among adults. Health Qual Life Outcomes. 2014;12:165.

57. Ng SK, Leung WK. Oral health-related quality of life and periodontal status. Community Dent Oral Epidemiol. 2006;34(2):114-22.

58. Needleman I, McGrath C, Floyd P, et al. Impact of oral health on the life quality of periodontal patients. J Clin Periodontol. 2004;31(6):454-7.

59. Zhang Q, Witter DJ, Gerritsen AE, et al. Functional dental status and oral health-related quality of life in an over 40 years old Chinese population. Clin Oral Investig. 2013;17(6):1471-80

60. Ozhayat EB. Influence of self-esteem and negative affectivity on oral healthrelated quality of life in patients with partial tooth loss. Community Dent Oral Epidemiol. 2013;41(5):466-72

61. Chankanka O, Levy SM, Warren JJ, et al. A literature review of aesthetic perceptions of dental fluorosis and relationships with psychosocial aspects/ oral health-related quality of life. Community Dent Oral Epidemiol. 2010; 38(2):97-109.

62. Isiekwe Gl, Sofola OO, Onigbogi OO, et al. Dental esthetics and oral healthrelated quality of life in young adults. Am J Orthod Dentofac Orthop. 2016; 150(4):627-36

63. Klages U, Bruckner A, Zentner A. Dental aesthetics, self-awareness, and oral health-related quality of life in young adults. Eur J Orthod. 2004;26(5):507-14.

64. Tsakos G, Sheiham A, lliffe S, et al. The impact of educational level on oral health-related quality of life in older people in London. Eur J Oral Sci. 2009; 117(3):286-92

65. Espinoza I, Thomson WM, Gamonal J, et al. Disparities in aspects of oralhealth-related quality of life among Chilean adults. Community Dent Oral Epidemiol. 2013;41(3):242-50.

66. Cohen J. Statistical power analysis for the behavioral sciences. 2nd. Hillsdale, NJ: Erlbaum; 1988

67. Norman GR, Sloan JA, Wyrwich KW. Interpretation of changes in healthrelated quality of life: the remarkable universality of half a standard deviation. Med Care. 2003;41(5):582-92.

68. Waller $\mathrm{N}$, John MT, Feuerstahler $\mathrm{L}$, et al. A 7-day recall period for a clinical application of the oral health impact profile questionnaire. Clin Oral Investig. 2016;20(1):91-9.

69. Yeh DY, Kuo HC, Yang YH, et al. The responsiveness of Patients' quality of life to dental caries treatment-a prospective study. PLoS One. 2016;11(10): e0164707.

70. Al Habashneh R, Khader YS, Salameh S. Use of the Arabic version of Oral health impact Profile-14 to evaluate the impact of periodontal disease on oral health-related quality of life among Jordanian adults. J Oral Sci. 2012; 54(1):113-20.

71. Llewellyn CD, Warnakulasuriya S. The impact of stomatological disease on oral health-related quality of life. Eur J Oral Sci. 2003;111(4):297-304.

72. Dahlstrom L, Carlsson GE. Temporomandibular disorders and oral health-related quality of life. A systematic review. Acta Odontol Scand. 2010;68(2):80-5.

73. Vermaire $J \mathrm{H}$, de Jongh $\mathrm{A}$, Aartman $\mathrm{H}$. Dental anxiety and quality of life: the effect of dental treatment. Community Dent Oral Epidemiol. 2008;36(5):409-16.

74. Thomason JM, Heydecke G, Feine JS, et al. How do patients perceive the benefit of reconstructive dentistry with regard to oral health-related quality of life and patient satisfaction? A systematic review. Clin Oral Implants Res. 2007;18(Suppl 3):168-88.
75. Sargozaie N, Moeintaghavi A, Shojaie H. Comparing the quality of life of patients requesting dental implants before and after implant. Open Dent J. 2017;11:485-91.

76. Marino R, Schofield M, Wright C, et al. Self-reported and clinically determined oral health status predictors for quality of life in dentate older migrant adults. Community Dent Oral Epidemiol. 2008;36(1):85-94.

77. Naito $M$, Yuasa $H$, Nomura $Y$, et al. Oral health status and health-related quality of life: a systematic review. J Oral Sci. 2006;48(1):1-7.

78. Fernandes MJ, Ruta DA, Ogden GR, et al. Assessing oral health-related quality of life in general dental practice in Scotland: validation of the OHIP14. Community Dent Oral Epidemiol. 2006;34(1):53-62.
Ready to submit your research? Choose BMC and benefit from:

- fast, convenient online submission

- thorough peer review by experienced researchers in your field

- rapid publication on acceptance

- support for research data, including large and complex data types

- gold Open Access which fosters wider collaboration and increased citations

- maximum visibility for your research: over $100 \mathrm{M}$ website views per year

At BMC, research is always in progress.

Learn more biomedcentral.com/submissions 